\title{
The Acute Effects of Steroid Administration on Pituitary Adrenal Secretion in the Dog*
}

\author{
Richard H. Egdahl $\dagger$ \\ (From the Department of Surgery, Medical College of Virginia, Richmond, Va.)
}

Prolonged steroid administration results in pituitary adrenal unresponsiveness. The mechanism appears to be decreased ACTH secretion, with resultant adrenal cortical atrophy (1). There is much controversy, however, concerning the acute effect of steroids on pituitary adrenal secretion, and there are several important unsettled problems. Evidence is conflicting about a possible direct inhibitory effect of steroids on the adrenal cortex. Some reports describe steroid inhibition of the pituitary adrenal cortical response to operative trauma. (2), whereas others find no diminution of normal responsiveness with acute administration of steroids (3). There is little information available about effects of steroids on the responses to other stimuli. And, finally, there is not agreement on the central nervous system site of steroid action. Some experiments suggest a direct effect on the anterior pituitary (4), but the bulk of work indicates an effect at the hypothalamic or higher level $(5,6)$. The present study was designed to provide at least partial answers to these questions. The potent synthetic steroid analogue, dexamethasone, was administered to dogs in which adrenal cortical function was measured by determining adrenal venous corticosteroid secretion.

\section{Methods}

Adult mongrel dogs, ranging in weight from 15 to 30 pounds, were used in these experiments. Adrenal venous cannulations were carried out according to the technique of Hume and Nelson (7). Adrenal venous 17-hydroxycorticosteroids were measured by the method of Peterson, Karrer, and Guerra (8), utilizing hemolyzed whole blood instead of plasma. Corticosteroid secretion rate was determined by multiplying adrenal

* Submitted for publication April 13, 1964; accepted July 16, 1964.

Supported in part by U. S. Public Health Service research grant AM-06372.

$\dagger$ Present address: Massachusetts Memorial Hospitals, Boston, Mass. venous blood flow by corticosteroid concentration. Hypophysectomies were performed by the transbuccal approach of Markowitz and Archibald (9). Removal of the entire brain down to the pons, leaving an isolated pituitary, or bilateral decortication was carried out according to techniques developed in our laboratories (10, 11). Dexamethasone phosphate, $100 \mathrm{mg}$ added to 1,000 $\mathrm{ml}$ of $0.9 \%$ sodium chloride solution, was infused at the rate of $50 \mathrm{ml}$ per hour in the inhibition experiments. In the hemorrhage experiments, approximately $500 \mathrm{ml}$ of blood was removed from the animal over a 20 -minute period, and adrenal venous samples were obtained before and after completion of hemorrhage. For the endotoxin experiments, $1.0 \mathrm{mg}$ of Escherichia coli lipopolysaccharide $\mathrm{B}^{2}$ was rapidly administered intravenously, and adrenal venous blood samples were taken before and 20 to 40 minutes after endotoxin. The animals subjected to ether anesthesia were given a single injection of sodium pentothal, and then anesthesia was maintained with ether throughout the rest of the experiment. Heavy canvas jackets were kept on the animals between sampling periods. Approximately $1 \mathrm{ml}$ of heparin was instilled into the adrenal venous catheter to prevent clotting at the end of an experimental period. We have been able to obtain adrenal venous samples in dogs under a variety of conditions for several weeks with this technique.

\section{Results}

The first group of experiments was carried out in dogs hypophysectomized 2 hours before the control period. Two and $10 \mathrm{mU}$ of ACTH were administered during the control period, and adrenal 17-hydroxycorticosteroid secretion per minute was measured 5 minutes after ACTH administration. Thirty minutes was allowed between the two different doses of ACTH to permit return to base-line values of corticosteroid secretion in the animals.

The results of these experiments are shown in Table I. The mean corticosteroid response to 2 $\mathrm{mU}$ of ACTH administered in the control pe-

1 Supplied through the courtesy of Merck, Sharp \& Dohme Research Laboratories, West Point, Pa.

2 Difco Laboratories, Detroit, Mich. 
riod was $6.1 \mu \mathrm{g}$, with an increase to $10.3 \mu \mathrm{g}$ after $10 \mathrm{mU}$ of ACTH. One hour after continuous intravenous infusion of dexamethasone, the mean responses after 2 and $10 \mathrm{mU}$ of ACTH were 5.3 and $1.2 \mu \mathrm{g}$, respectively. Statistical analysis reveals no significant difference between the responses before or during the dexamethasone infusion $(p>0.5)$ at either dosage. Figure 1 outlines a detailed protocol of one of these experiments. The adrenal cortical response to 2 or $10 \mathrm{mU}$ of ACTH is clearly unaffected by dexamethasone infusion.

The second series of experiments involved three groups of dogs : 23 control animals in which operative response after adrenal vein cannulation and ACTH responses were observed; an experimental group of 16 animals in which adrenal vein cannulation was carried out with dexamethasone infusion for 1 hour before, and during, operation; and 18 dogs in which "resting" corticosteroid secretion was measured the day after adrenal venous cannulation and contrasted with response after $1 \mathrm{U}$ of ACTH intravenously. Table II summarizes the data in these animals. The mean corticosteroid response after adrenal vein cannulation in the control series of animals was 11.2 $\mu \mathrm{g}$, as contrasted to a value of $3.7 \mu \mathrm{g}$ in series $\mathrm{B}$ in which the animals underwent the same operation but received a dexamethasone infusion. This difference is significant $(p<0.02,>0.01)$ and indicates an inhibitory effect of the dexamethasone infusion on the adrenal cortical response to adrenal vein cannulation. When the cannulation response

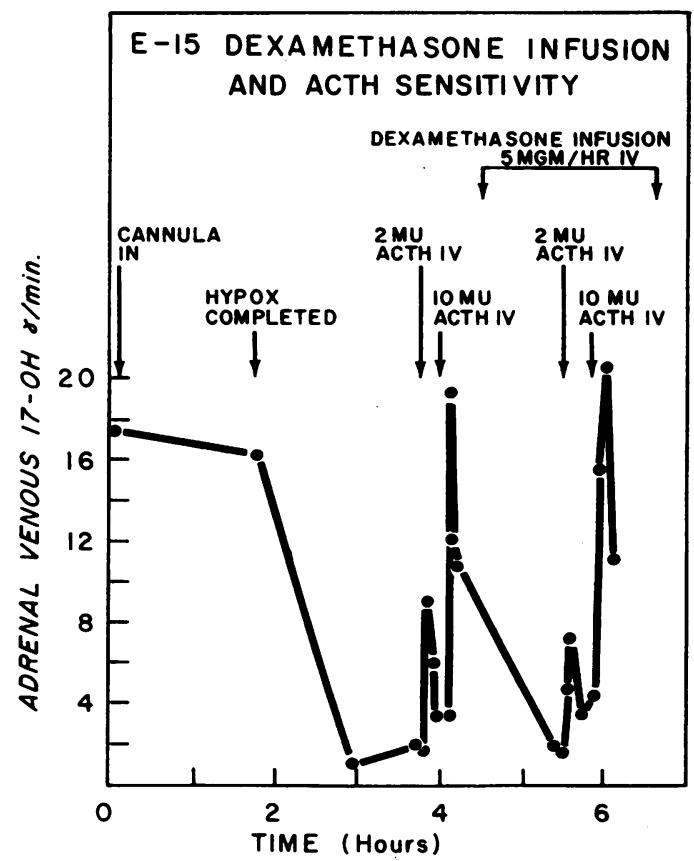

Fig. 1. ACTH SENSITIVITY OF HYPOPHYSECTOMIZED DOGS BEFORE AND DURING DEXAMETHASONE INFUSION. $17-\mathrm{OH}=17$-hydroxycorticosteroids $;$ hypox $=$ hypophysectomized.

of the animals receiving dexamethasone infusion $(3.7 \mu \mathrm{g})$ was contrasted with the resting response of animals the day after adrenal vein cannulation $(1.1 \mu \mathrm{g})$, the difference was highly significant $(p<0.001)$ and indicates that the response to operative trauma in the dexamethasoneinfused animals, while subnormal, was definite.

The third group of experiments was carried out

TABLE I

Effect of dexamethasone infusion on sensitivity of adrenal cortex to ACTH administration*

\begin{tabular}{|c|c|c|c|c|}
\hline \multirow{2}{*}{$\begin{array}{l}\text { Experiment } \\
\text { no. }\end{array}$} & \multicolumn{2}{|c|}{ Control period } & \multicolumn{2}{|c|}{$\begin{array}{l}1 \text { hour after start of continuous } \\
\text { infusion of dexamethasone } \\
(5 \mathrm{mg} / \text { hour iv })\end{array}$} \\
\hline & $2 \mathrm{mU}$ ACTH & $10 \mathrm{mU}$ ACTH & $2 \mathrm{mU} \mathrm{ACTH}$ & $10 \mathrm{mU} \mathrm{ACTH}$ \\
\hline & \multicolumn{2}{|c|}{$\mu g /$ minute } & \multicolumn{2}{|c|}{$\mu g /$ minute } \\
\hline $\begin{array}{l}\text { E-1 } \\
\text { E-4 } \\
E-5 \\
E-6 \\
H-10 \\
E-13 \\
E-15\end{array}$ & $\begin{array}{r}7.4 \dagger \\
8.0 \\
10.4 \\
0.7 \\
1.3 \\
6.0 \\
9.1\end{array}$ & $\begin{array}{r}5.5 \\
18.6 \\
4.7 \\
2.5 \\
18.2 \\
12.2\end{array}$ & $\begin{array}{r}2.7 \\
6.2 \\
8.7 \\
1.9 \\
3.1 \\
10.1 \\
4.4\end{array}$ & $\begin{array}{r}12.8 \\
9.9 \\
12.8 \\
7.4 \\
6.8 \\
13.2 \\
15.7\end{array}$ \\
\hline Mean & $6.1 \pm 1.4 \ddagger$ & $10.3 \pm 2.9$ & $5.3 \pm 1.2$ & $11.2 \pm 1.2$ \\
\hline
\end{tabular}

* Dogs were hypophysectomized 2 hours before the control period.

+ Corticosteroid secretion from right adrenal gland. All samples obtained 5 minutes after.ACTH administration. $\ddagger$ Standard error of the mean. 
TABLE II

Effect of dexamethasone infusion on adrenal cortical response to surgical trauma of adrenal vein cannulation

\begin{tabular}{|c|c|c|c|c|c|c|c|c|}
\hline \multicolumn{3}{|c|}{$\begin{array}{l}\text { A. Control series of dogs with } \\
\text { adrenal vein cannulation }\end{array}$} & \multicolumn{3}{|c|}{$\begin{array}{l}\text { B. Series of dogs receiving continu- } \\
\text { ous dexamethasone infusion, } 5 \mathrm{mg} / \\
\text { hour iv. Infusion started } 1 \text { hour } \\
\text { before beginning cannulation of } \\
\text { adrenal vein }\end{array}$} & \multicolumn{3}{|c|}{$\begin{array}{l}\text { C. Control series of dogs with values } \\
\text { for "resting" adrenal cortical secre- } \\
\text { tion } 24 \text { hours after adrenal vein } \\
\text { cannulation }\end{array}$} \\
\hline $\begin{array}{l}\text { Experiment } \\
\text { no. }\end{array}$ & $\begin{array}{l}\text { Cannulation } \\
\text { completed }\end{array}$ & $\begin{array}{l}5 \text { minutes after } \\
1 \text { U ACTH iv }\end{array}$ & $\begin{array}{l}\text { Experiment } \\
\text { no. }\end{array}$ & $\begin{array}{l}\text { Cannulation } \\
\text { completed }\end{array}$ & $\begin{array}{l}5 \text { minutes after } \\
1 \text { UACTH iv }\end{array}$ & $\begin{array}{c}\text { Experiment } \\
\text { no. }\end{array}$ & $\begin{array}{l}\text { adrenal vein } \\
\text { cannulation }\end{array}$ & $\begin{array}{l}5 \text { minutes after } \\
1 \mathrm{UACTH} \text { iv }\end{array}$ \\
\hline & \multicolumn{2}{|c|}{$\mu g /$ minute } & \multicolumn{3}{|c|}{$\mu \mathrm{g} /$ minute } & \multicolumn{3}{|c|}{$\mu g /$ minute } \\
\hline EII-1 & $10.8^{*}$ & 13.0 & ED-10 & 4.1 & 18.4 & EM-1 & 1.7 & 8.7 \\
\hline EI-4 & 10.4 & 10.0 & B-288 & 1.2 & 20.8 & EE-1 & 0.6 & 9.1 \\
\hline EI-5 & 13.2 & 16.0 & ED-15 & 1.6 & 10.8 & EE-2 & 0.6 & 11.5 \\
\hline EI-9 & 11.2 & 11.6 & BP-60 & 2.2 & 11.4 & VP-30 & 0.2 & 13.0 \\
\hline EI-10 & 12.2 & 13.4 & ED-9 & 4.6 & 11.8 & VP-28 & 2.0 & 16.4 \\
\hline EI-11 & 13.4 & 8.8 & ED-7 & 4.6 & 9.8 & VP-29 & 0.1 & 13.8 \\
\hline EI-13 & 9.2 & 14.8 & ED-6 & 0.8 & 6.0 & VP-22 & 0.0 & 10.4 \\
\hline B-336 & 10.6 & 19.0 & ED-5 & 2.6 & 5.8 & VP-24 & 0.8 & 13.2 \\
\hline BDJ-2 & 22.8 & 22.2 & ED-4 & 5.8 & 12.4 & VP-20 & 1.8 & 12.5 \\
\hline B-366 & 14.8 & 13.8 & ED-3 & 0.8 & 6.8 & VP-21 & 0.5 & 13.5 \\
\hline В-АСТН-5 & 13.0 & 16.2 & ED-2 & 2.2 & 10.6 & EN-14 & 0.6 & 21.5 \\
\hline B-214 & 12.2 & 12.0 & ED-1 & 0.8 & 15.9 & EN-12 & 1.9 & 12.6 \\
\hline EN-10 & 12.8 & 16.0 & B1-63 & 9.6 & 26.4 & EN-16 & 4.2 & 23.8 \\
\hline EN-9 & 8.2 & 13.8 & B-245 & 4.6 & 6.8 & EN-10 & 1.1 & 8.1 \\
\hline EN-11 & 11.7 & 12.4 & ED-1-d & 6.0 & 12.4 & EN-11 & 1.3 & 17.6 \\
\hline EN-15 & 8.8 & 13.0 & ED-12 & 7.0 & 12.0 & EN-18 & 0.5 & 13.4 \\
\hline EN-13 & 7.2 & 12.1 & & & & EN-15 & 1.0 & 14.6 \\
\hline EN-6 & 7.2 & 6.6 & & & & EN-13 & 0.6 & 8.8 \\
\hline B-270 & 8.4 & 9.6 & Mean & $3.7 \pm 0.6$ & $12.4 \pm 1.4$ & & & \\
\hline B-272 & 11.2 & 10.8 & & & & Mean & $1.1 \pm 0.2$ & $13.5 \pm 1.0$ \\
\hline B-273 & 8.8 & 9.0 & & & & & & \\
\hline B-278 & 10.4 & 10.8 & & & & & & \\
\hline EN-1 & 8.0 & 11.7 & & & & & & \\
\hline Mean & $11.2 \pm 0.7 \dagger$ & $12.9 \pm 0.7$ & & & & & & \\
\hline
\end{tabular}

* Corticosteroid secretion from right adrenal gland.

$\uparrow$ Standard error of the mean.

in a series of dogs with "chronic" adrenal venous cannulas in which adrenal vein cannulation had been carried out the day before the experiment. A significant adrenal cortical response was observed after both hemorrhage and endotoxin administration in this group of dexamethasone-infused dogs, as shown in Table III. These responses were maximal as shown by a failure of exogenous ACTH to increase further corticosteroid secretion. These maximal adrenal cortical responses represent confirmation of the stimulatory effects of hemorrhage (7) and endotoxin (12) on adrenal cortical secretion previously described from our laboratories and those of others. In marked contrast is the complete inhibition of response to ether anesthesia that is observed when dexamethasone infusion is given before ether anesthesia. Reference to part $\mathrm{C}$ of Table III indicates that there is no significant difference between the mean corticosteroid secretion of $1.3 \mu \mathrm{g}$ in the control period and that of $2.4 \mu \mathrm{g}$ after 1 hour of continuous ether anesthesia $(\mathrm{p}<0.2$ and $>0.1)$. ACTH administration resulted in a response of $13.7 \mu \mathrm{g}$, which is highly significant when contrasted to the secretion observed 1 hour after ether anesthesia with dexamethasone infusion $(p<0.005,>0.001)$. These experiments indicate that dexamethasone infu,sion does not alter the normal maximal response to hemorrhage or endotoxin administration but appears to prevent completely the expected maximal adrenal cortical activation after ether anesthesia in dogs (13). In addition, these experiments demonstrate that dexamethasone infusion alone does not result in increased corticosteroid content in adrenal venous blood.

The final group of experiments is divided into two parts. The first characterizes the adrenal corticosteroid response in dogs with dexamethasone infusion started before brain removal and carried on throughout the remainder of the experiment. It can be seen in Table IV that 1 hour after brain removal the corticosteroid secretion was $1.8 \mu \mathrm{g}$ per minute, whereas 3 to 5 
hours after brain removal the mean value was 7.0 $\mu \mathrm{g}$ per minute. Figure 2 illustrates a more detailed protocol of one of these animals. Despite the continuous intravenous administration of 5 $\mathrm{mg}$ of dexamethasone per hour, a significant operative response to adrenal vein cannulation and brain exposure was observed with depression of corticosteroid secretion levels 1 hour after removal of the brain. However, secretion increased during the next 2 hours, and administration of $1 \mathrm{U}$ of ACTH approximately 3 hours after brain removal resulted in a further significant increase in corticosteroid secretion.

The second portion of these experiments revealed no decrease in the maximal corticosteroid secretion that followed bilateral decortication, de-

TABLE III

Effect of dexamethasone infusion (5 mg per hour iv) on adrenal cortical response to hemorrhage, endotoxin, and ether anesthesia*

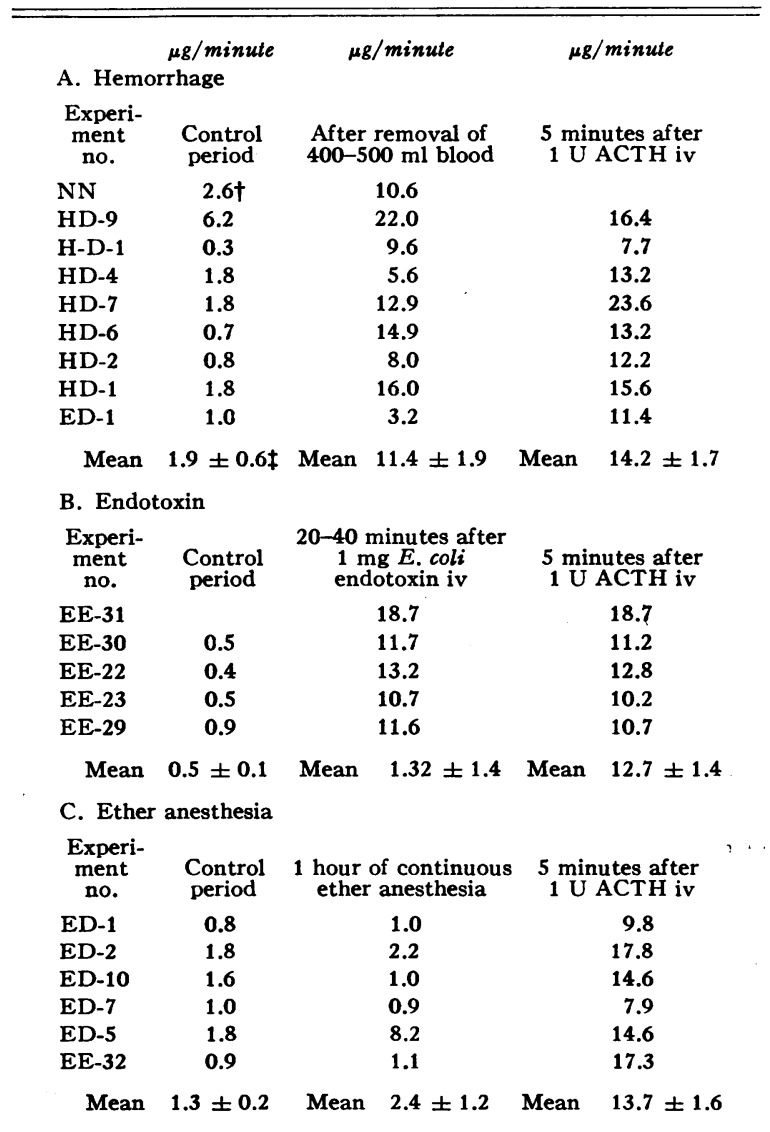

* Infusion was begun 1 hour before stimulus and carried on throughout the experiment.

t Corticosteroid secretion from right adrenal gland.

\$ Standard error of the mean.
TABLE IV

Effect of dexamethasone infusion (5 mg per hour iv) on adrenal cortical secretion in dogs with isolated pituitaries or bilateral decortication*

\begin{tabular}{lcc}
\hline \hline \multicolumn{3}{c}{$\mu g /$ minute } \\
$\begin{array}{l}\text { A. Isolated pituitaries } \\
\text { Experiment } \\
\text { no. }\end{array}$ & $\begin{array}{c}\text { 1 hour after } \\
\text { brain removal }\end{array}$ & $\begin{array}{c}3-5 \text { hours after } \\
\text { brain removal }\end{array}$ \\
B-401 & $0.6 \dagger$ & 4.2 \\
B-400 & 1.4 & 6.4 \\
B-398 & 2.6 & 11.4 \\
B-389 & 0.6 & 10.8 \\
B-390 & 0.6 & 0.6 \\
B-391 & 0.9 & 11.8 \\
B-392 & 5.7 & 6.0 \\
B-395 & 1.8 & 6.5 \\
B-397 & 2.2 & 4.9 \\
Mean & $1.8 \pm 0.5 \ddagger$ & $7.0 \pm 1.2$ \\
B. Bilateral decortication & \\
Experiment & $10-18$ hours after & 5 minutes after \\
no. & bilateral decortication & 1 U ACTH iv \\
DD-10-A & 13.2 & \\
DD-10 & 38.6 & 34.8 \\
DD-7 & 18.6 & 17.8 \\
B-404 & 11.4 & 10.0 \\
B-402 & 23.0 & 21.8 \\
B-403 & 23.9 & $21.1 \pm 5.2$ \\
Mean & $21.5 \pm 4.0 \dagger$ & \\
& &
\end{tabular}

* Infusion was begun before brain removal or decortication and carried on throughout the experiment

† Corticosteroid secretion from right adrenal gland.

$\ddagger$ Standard error of the mean.

spite the constant infusion of dexamethasone throughout the experiment. The mean value of adrenal cortical secretion 10 to 18 hours after bilateral decortication was $21.5 \mu \mathrm{g}$ per minute, with an ACTH response of $21.1 \mu \mathrm{g}$ per minute. Dexamethasone was ineffective, therefore, in preventing the adrenal cortical hypersecretion that occurs after bilateral decortication.

\section{Discussion}

There is little specifically pertinent literature concerning a possible direct inhibitory effect of steroids on the adrenal cortical response to ACTH. Péron, Moncloa, and Dorfman (14), using very high doses of corticosterone, found less adrenal content of corticosterone in rats given ACTH than when corticosterone was not administered. Black and co-workers (15), infusing high concentrations of hydrocortisone into the isolated perfused adrenal gland of the dog, demonstrated inhibition of hydrocortisone production. Experiments in dogs with adrenal venous cannulas by Ganong (16) have failed to confirm a direct ef- 


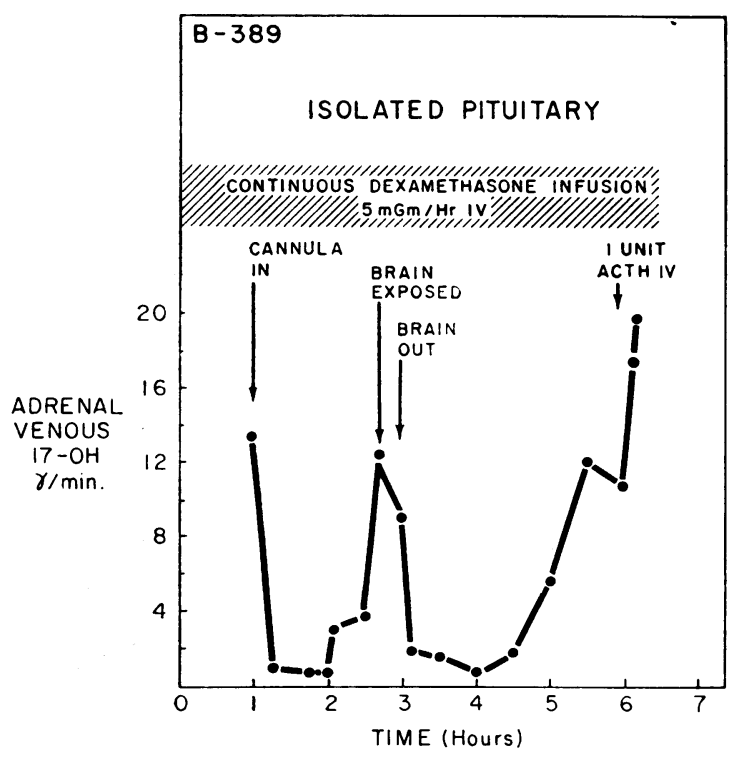

Fig. 2. Corticosteroid Secretion in Dogs ReceivING CONSTANT INFUSION OF DEXAMETHASONE. Operative procedures were adrenal vein cannulation and brain removal, with ACTH administration at end of experiment.

fect on adrenal cortical responsiveness to ACTH after infusion of physiological concentrations of hydrocortisone. The experiments presented in part one of the present study are in agreement with those of Ganong and appear to establish that the administration of pharmacological doses of dexamethasone does not decrease the adrenal cortical responsiveness to threshold doses of ACTH in the dog. The doses of dexamethasone utilized in this study are considered pharmacologic because they far exceed the potential for endogenous production of biologically active corticosteroids by the dog. It is emphasized that the experiments of this paper are concerned only with the acute effects of steroid administration and do not provide any basis for speculations concerning possible long-term effects of steroid administration on adrenal cortical responsiveness to ACTH.

Previous experimental work is also conflicting concerning the possible inhibitory effects of steroid administration on the adrenal cortical response to trauma. Richards and Pruitt (2) were able to inhibit completely the expected adrenal cortical response of dogs to adrenal vein cannulation by infusions of hydrocortisone. Although our experiments demonstrate a decreased adrenal cortical response to adrenal vein cannulation com- pared to normal, the response is significant when compared to resting or basal secretion. It is possible that this difference between our results and those of Richards and Pruitt is due to more rapid cannulation of the adrenal vein in our experiments. We have found that the adrenal cortical response to trauma of animals receiving dexamethasone infusion may decrease rapidly after cannulation. Estep, Island, Ney, and Liddle (3) were unable to prevent the increase in peripheral blood corticosteroid levels that occurs after laparotomy in patients by administering dexamethasone intravenously before and during operation. Myers and colleagues (17), on the other hand, did partially prevent the peripheral blood corticosteroid response after operative trauma by administering triamcinolone. The difference between our results and those of Estep and co-workers is probably based on species variation, the fact that the patient studies involved measurements of peripheral blood levels of steroids and not secretion rates, and differences in magnitude of operative trauma. Hedner and Rerup (18) found that dexamethasone inhibited completely the stimulating effect of ether and inhibited partially the increase in plasma corticosteroid levels after unilateral adrenalectomy. Kendall (19) demonstrated maximal depression of adrenal venous corticosteroid secretion in rats 4 to 8 hours after the administration of $2 \mathrm{mg}$ of dexamethasone. Hodges and Jones (20) were able to block the acute release of ACTH in the rat by pretreatment with cortisol, and Hamburger (21) found that dexamethasone is the most potent inhibitor of the adrenal cortical response to adrenalectomy in the rat. The data of the present experiments, taken in conjunction with these other studies, demonstrate that the administration of steroids may modify the adrenal cortical response to operative trauma. Because of the widely divergent conditions of the experiments in the various reported studies, particular care must be taken in contrasting results of different workers. Factors that must be considered in evaluating data in this area include steroid dose, rate of steroid administration, species of animal, magnitude of operative trauma, and method of assessing adrenal cortical function. Preliminary experiments in our laboratory revealed that smaller 
amounts of dexamethasone give less inhibition; therefore, pharmacological doses of steroid were used.

Dexamethasone did not prevent the expected maximal adrenal cortical stimulation after hemorrhage and endotoxin administration. On the other hand, in confirmation of Kendall (19) and Hedner and Rerup (18), dexamethasone completely prevented the expected maximal response to ether anesthesia. Studies in our laboratories and those of others have revealed that maximal and sustained corticosteroid secretion is present $\frac{1}{2}$ to 1 hour after ether anesthesia (13). It appears, therefore, either that hemorrhage and endotoxin are stronger stimuli to a common mechanism of ACTH release, or that ether acts through different pathways that are blocked by steroid administration. There is nothing in the data of this or other reports that permits a choice between these two possibilities.

Our final group of experiments with brain removal and bilateral decortication indicates that dexamethasone administration does not prevent the adrenal cortical hypersecretion that these animals demonstrate and that has previously been reported in detail from our laboratories $(10,22)$. The previously described pattern of depressed corticosteroid secretion 1 to 2 hours after brain removal, with gradual increase to elevated but submaximal levels, was observed in dogs with isolated pituitaries receiving dexamethasone infusions. These data are in no way different from those observed in dogs not receiving steroids and appear to offer evidence for an extrapituitary site of steroid inhibition.

There are basically two possible ways to explain the findings of corticosteroid secretions that are elevated above base line but are less than maximal in dogs with isolated pituitaries. A weak stimulatory hormone or other systemic agent may be acting on the pituitary to cause ACTH release. On the other hand, if the pituitary in the intact animal is constantly bathed in a mixture of excitatory and inhibitory hormones with respect to $\mathrm{ACTH}$ release, it is possible that removal of the source of such hormones results in a pituitary whose intrinsic ACTH-releasing activity is revealed. Current studies in our laboratories indicate that peripheral blood from dogs with isolated pituitaries is ineffective in causing $\mathrm{ACTH}$ release when injected into the carotid artery of normal dogs. There is, therefore, no evidence for a systemic substance causing ACTH secretion from the isolated pituitary. Kendall, Matsuda, Duyck, and Greer (23) found that dexamethasone does suppress the moderately elevated ACTH secretion in rats with median eminence islands, and our studies taken together with his suggest a hypothalamic site for steroid inhibition of ACTH secretion. Several groups of workers $(5,6)$ have found that implantation of steroids into the hypothalamus, but not into the pituitary, is effective in inhibiting ACTH secretion. These findings would also appear to support a hypothalamic site for steroid action on pituitary adrenal responsiveness. If there are both excitatory and inhibitory hormones to pituitary ACTH secretion in the intact animal, steroids may act either by inhibiting release of the stimulatory hormone or enhancing release of the postulated inhibitor, or both.

The resolution of these problems awaits further work on hypothalamic and other central nervous system hormones that control ACTH secretion, understanding of the pathways for their control in the intact animal, and studies of the effect of steroids on their production and release.

\section{Summary}

1. Dexamethasone infusion did not alter the ACTH sensitivity of hypophysectomized dogs, suggesting that steroids have no direct effect on the adrenal cortex.

2. Dexamethasone administration partially prevented the increase in adrenal cortical secretion after operative trauma and completely abolished the expected stimulatory effect of ether anesthesia. On the other hand, steroid administration did not modify the expected maximal response to hemorrhage, endotoxin administration, or bilateral decortication.

3. The infusion of pharmacological doses of dexamethasone was ineffective in modifying the adrenal cortical hypersecretion of dogs with isolated pituitaries. There is evidence in favor of an extrapituitary site for steroid inhibition of ACTH secretion. 


\section{References}

1. Meakin, J. W., M. S. Tantongco, J. Crabbé, T. B. Bayles, and D. H. Nelson. Pituitary-adrenal function following long-term steroid therapy. Amer. J. Med. 1960, 29, 459.

2. Richards, J. B., and R. L. Pruitt. Hydrocortisone suppression of stress-induced adrenal 17-hydroxycorticosteroid secretion in dogs. Endocrinology 1957, 60, 99.

3. Estep, H. L., D. P. Island, R. L. Ney, and G. W. Liddle. Pituitary-adrenal dynamics during surgical stress. J. clin. Endocr. 1963, 23, 419.

4. Rose, S., and J. Nelson. Hydrocortisone and A.C.T.H. release. Aust. J. exp. Biol. med. Sci. 1956, 34, 77.

5. Smelik, P. G., and C. H. Sawyer. Effects of implantation of cortisol into the brain stem or pituitary gland on the adrenal response to stress in the rabbit. Acta endocr. (Kbh.) 1962, 41, 561.

6. Davidson, J. M., and S. Feldman. Cerebral involvement in the inhibition of ACTH secretion by hydrocortisone. Endocrinology 1963, 72, 936.

7. Hume, D. M., and D. H. Nelson. Adrenal cortical function in surgical shock. Surg. Forum 1954, 5, 568.

8. Peterson, R. E., A. Karrer, and S. L. Guerra. Evaluation of Silber-Porter procedure for determination of plasma hydrocortisone. Analyt. Chem. 1957, 29, 144.

9. Markowitz, J., and J. Archibald. Transbuccal hypophysectomy in the dog. Canad. J. Biochem. 1956, $34,422$.

10. Egdahl, R. H. Adrenal cortical and medullary responses to trauma in dogs with isolated pituitaries. Endocrinology 1960, 66, 200.

11. Egdahl, R. H. Cerebral cortical inhibition of pituitary-adrenal secretion. Endocrinology 1961, 68, 574.

12. Egdahl, R. H. The differential response of the adrenal cortex and medulla to bacterial endotoxin. J. clin. Invest. 1959, 38, 1120.
13. Hume, D. M. The method of hypothalamic regulation of pituitary and adrenal secretion in response to trauma in Pathophysiologia Diencephalica. Stuttgart, Springer-Verlag, 1956, p. 217.

14. Péron, F. G., F. Moncloa, and R. I. Dorfman. Studies on the possible inhibitory effect of corticosterone on corticosteroidogenesis at the adrenal level in the rat. Endocrinology 1960, 67, 379.

15. Black, W. C., R. S. Crampton, A. S. Verdesca, R. I. Nedeljkovic, and J. G. Hilton. Inhibitory effect of hydrocortisone and analogues on adrenocortical secretion in dogs. Amer. J. Physiol. 1961, 201, 1057.

16. Ganong, W. F. The central nervous system and the synthesis and release of adrenocorticotropic hormone in Advances in Neuroendocrinology. Urbana, University of Illinois Press, 1963, p. 92.

17. Myers, J. L., L. J. Marks, E. T. O'Hara, J. W. Heizer, and $H$. Liberman. Regulatory function of circulating corticosteroids in the pituitaryadrenal response to surgical operation. Ann. Surg. 1961, 154, 859.

18. Hedner, P., and C. Rerup. Plasma corticosteroid levels and adrenal ascorbic acid after intravenous corticotrophin injections and «stressful» stimuli in the rat. Acta Endocr. (Kbh.) 1962, 39, 527.

19. Kendall, J. W. Quantitative and temporal studies on effect of dexamethasone on corticosterone secretion in the rat. Proc. Soc. exp. Biol. (N. Y.) 1961, 107, 926.

20. Hodges, J. R., and M. T. Jones. Corticotrophin release in the cortisol-treated rat. J. Physiol. (Lond.) 1962, 163, 391.

21. Hamburger, C. Assay of corticotrophin prednisolone pretreatment instead of hypophysectomy in the adrenal ascorbic acid depletion test. Acta. Endocr. (Kbh.) 1960, 35, 594.

22. Egdahl, R. H. Further studies on adrenal cortical function in dogs with isolated pituitaries. Endocrinology 1962, 71, 926.

23. Kendall, J. W., Jr., K. Matsuda, C. Duyck, and M. A. Greer. Studies of the location of the receptor site for negative feedback control of ACTH release. Endocrinology 1964, 74, 279. 